\title{
Application of Fluid-Solid Coupling Theory in Casing Damage Forecast
}

\author{
J. J. Liu ${ }^{1 *}$, G. H. Pei ${ }^{1}$, X. He ${ }^{1}$, X. G. $\operatorname{Liu}^{2}$ \\ ${ }^{1}$ Institute of Poromechanics, Wuhan Polytechnic University, Wuhan 430023, China \\ ${ }^{2}$ Institute of Porous Flow and Fluid Mechanics, Chinese Academy of Sciences, Langfang 065007, China \\ Email: liujj@whpu.edu.cn
}

\begin{abstract}
Casing damage has become a very serious concern in China since 1970s. Along with adoption of highpressure water injection and high pressure hydraulic fracturing in oil fields, casing damage become a challenging technical difficulty in the Chinese and international petroleum industry. Many researchers have been devoted to solve the problems and had identified important factors affecting casing damage. such as geologic structure, development operation and drilling program. Although stress concentration around well bore is the direct reason of casing damage, it is the flow field change that induced geostress redistribution. Therefore, it is necessary to study the fluid-solid coupling during oil development to identify casing damage mechanisms.

According to the casing damage characters, casing damages induced by seepage can be classified into three kinds: shear-sliding damage, tension damage, and squeeze damage. Shear damage is induced by geologic fault slippage because water or oil flow into fault, and intenerates the mechanical parameters. When porous pressure increases to critical value, fault will slippage, and cause casing collapse. Tensile damage is induced by vertical strata displacement. When large volume water is injected into reservoir porous pressure rises, and leads to strata elevated. If the exceeds the casing's tensile strength, casing pipe will be destabilized. Extrusion casing damage is induced by large pressure gradient around the well bore as a pressure releasing effect in the water injection wells.

Based on fluid-solid coupling theory, the authors analyzed the mechanism of the 3 kinds casing damage and presented mathematical models. Using 3-D finite element method, the authors simulated the rock deformation patters causing casing damages in Daqing oil field, China, during water-flooding operations. According to the simulation results, some technical measures and critical injection pressure to prevent casing damage are given in the end for Daqing oil field.
\end{abstract}

\section{REFERENCES}

1. Hu ZB. Casing failure mechanisms and protection measures of oil and water well in Daqing oil field. Oil Drilling and Production, 1998; 20(5): 95-99

2. Liu JZ, Liu XL. Coupling mechanics models of casing deformation. Acta Petrolei Sinica, 2001; 22(3): $75-82$

3. Yin ZM. Mechanism of casing damage in Saertu south pool of Daqing oil field. Thesis for doctoral degreee of Chinese Academy of Sciences, 2000

4. Wang ZM. Casing damage of Oil and Water well and controlling method. Petroleum Industrial Press, 1994

5. Liu JJ., Liu XG., Hu YR. Study on fluid flow through low permeability rescrvoir. Chinese Journal of Rock Mechanics and Engineering, 2001; 21: 48-54 